\title{
QUANTIFICAÇÃO DE EROSÃO EM SISTEMAS AGROFLORESTAIS E CONVENCIONAIS NA ZONA DA MATA DE MINAS GERAIS ${ }^{1}$
}

\author{
Fernando Silveira Franco ${ }^{2}$, Laércio Couto ${ }^{3}$, Anor Fiorini de Carvalho ${ }^{4}$, Ivo Jucksch ${ }^{4}$, Elpídio Inácio Fernandes
} Filho $^{4}$, Elias Silva ${ }^{3}$ e João Augusto Alves Meira Neto

\begin{abstract}
RESUMO - A Zona da Mata de Minas Gerais é caracterizada por topografia forte ondulada, com solos intemperizados com baixa fertilidade natural e regime pluviométrico capaz de sustentar uma vegetação florestal. A ocupação da terra é minifundiária, predominando a agricultura familiar, que sofre as conseqüências da modernização da agricultura, exigindo uso intensivo do solo, o que, conseqüentemente, promove perdas de solo, água e nutrientes por erosão. Uma das alternativas propostas para redução das perdas por processos erosivos foi a implantação de sistemas agroflorestais. O objetivo deste estudo foi comparar as perdas por erosão em sistemas agroflorestais implantados em propriedades de pequenos agricultores com as perdas em sistemas convencionais. Os sistemas foram implantados como unidades experimentais de observação das condições socioambientais dos agricultores, utilizando metodologias participativas. Estas unidades experimentais apresentam dificuldades para quantificação da erosão, quando são usadas metodologias convencionais. A dinâmica do manejo utilizado pelos agricultores dificulta o uso de métodos que exigem a implantação de equipamentos permanentes. Além disto, os métodos que exigem o isolamento das parcelas produzem efeitos de borda que mascaram os resultados, quando comparados com os do sistema aberto conduzido por agricultores. Desta forma, foi desenvolvido um coletor de água e solo para superar tais limitações. O equipamento é composto por uma "mesa", que é inserida no solo, acoplada a uma calha móvel que sustenta um saco plástico. A água e o solo coletados no saco plástico são quantificados e analisados. Foram instalados coletores em 25 unidades de observação, sendo 14 em sistemas convencionais e $11 \mathrm{em}$ sistemas agroflorestais. A energia dos eventos erosivos foi calculada a partir de pluviogramas, para estimar as perdas potenciais anuais dos sistemas. Os dados foram coletados na estação chuvosa de 1998/ 1999. As perdas totais de solo, carbono orgânico e nutrientes dos sistemas convencionais, estimadas para um ano, foram significativamente maiores que as dos sistemas agroflorestais, o que indica a maior sustentabilidade ecológica destes últimos e comprova que eles são capazes de conservar os recursos naturais, evidenciando a importância da conversão dos sistemas convencionais em sistemas ecologicamente sustentáveis.
\end{abstract}

Palavras-chave: Uso da terra, conservação do solo, sustentabilidade e experimentação participativa.

\section{EVALUATION OF EROSION UNDER AGROFORESTRY AND CONVENTIONAL SYSTEMS IN ZONA DA MATA DE MINAS GERAIS}

\begin{abstract}
Zona da Mata de Minas Gerais is characterized by steep slopes, weathered soils with low natural fertility and precipitation capable to sustain a forest vegetation. Most of the land owners are small farmers, who suffer the consequences of modern agricultural technology, which demands intensive use of the land, causing soil, water and nutrient losses due to erosion. One of the alternatives proposed for the reduction of the erosive losses is to implement alternative agroforestry systems. The objective of this study is to compare losses due to erosion in agroforestry systems established in small farms under conventional systems. The systems were established as experimental units of observation under the existing environmental conditions, using participatory methodologies. It was difficult to quantify erosion using conventional methodologies. The management dynamics used by the farmers hinders the use of methods that require permanent equipment. Besides, methods demanding isolation of
\end{abstract}

1 Recebido para publicação em 18.4.2001.

Aceito para publicação em 3.12.2002.

2 Eng. Florestal, D.S. Agrossilvicultura - Apoio CNPq e WWF, < fsilveirafranco@aol.com>. ${ }^{3}$ Dep. de Engenharia Florestal da Universidade Federal de Viçosa - UFV, 36571-000 Viçosa-MG; ${ }^{4}$ Dep. de Solos da UFV; ${ }^{5}$ Dep. de Biologia Vegetal da UFV. 
sample areas cause border effects that disturb the results, when compared with the open systems used by the farmers. Thus, a water and soil collector was developed to overcome these limitations. The equipment is composed by a "board" that is inserted in the soil, coupled to a mobile gutter that sustains a bag. The water and the soil collected in the bag are quantified and analyzed. This device was installed in 25 observation units, 14 under conventional and 11 under agroforestry systems. The energy of the erosive events was calculated from pluviograms to estimate the annual potential losses of the systems. Data were collected in the 1998/1999 rainy season. The total losses of soil, organic matter and nutrients under the conventional systems, estimated for one year, were significantly greater than those under the agroforestry systems, indicating a greater ecological sustainability of the latter, proving that agroforestry systems are able to preserve natural resources, stressing the need to convert conventional systems into ecologically sustainable systems.

Key words: $\quad$ Land use, soil conservation, sustainability and participatory research.

\section{INTRODUÇÃO}

A produção agrícola atual da Zona da Mata apresenta três características principais: ocupação da terra antiga, pequena produção e práticas agrícolas tradicionais (Gomes, 1986). As atividades agrícolas são pastagem e produção de café, freqüentemente consorciada com feijão e, ou, milho. A região está inserida no domínio tropical atlântico, e sua cobertura vegetal é representada pela Floresta Estacional Semidecidual, que foi inicialmente substituída por plantações de café. Tal substituição quebrou a eficiente ciclagem de nutrientes do ecossistema florestal e reduziu drasticamente a fertilidade do solo em algumas décadas, principalmente em virtude da erosão e da exportação de nutrientes pelas colheitas. Este processo contribuiu ainda mais para o desmatamento, devido à procura de solos mais férteis para implantação de café (Dean, 1996).

Enquanto isso, as pastagens e as culturas de subsistência principais como milho, feijão e cana-de-açúcar substituíram lavouras de café antigas e depauperadas. Aliado a esses fatores, a adoção de um modelo tecnológico introduzido pela Revolução Verde contribuiu para a degradação ambiental e o enfraquecimento da agricultura familiar como um empreendimento econômico, principalmente pela dependência de monoculturas e de insumos externos (Ferrari, 1996). Apesar disto, a agricultura familiar mantém sua importância vital para a região, principalmente na produção de culturas de subsistência (Gomes, 1986). Em resumo, a maioria dos agroecossistemas na região apresenta, atualmente, baixa produtividade devido ao histórico de uso intensivo de terra, com práticas não-adaptadas ao ambiente, como os plantios de café sem trabalhos de conservação do solo (Ferrari, 1996).
Como mencionado, a erosão tem sido um dos principais fatores responsáveis pela degradação ambiental na região, sendo apontada pelos agricultores como uma das causas das baixas produtividades das culturas agrícolas, em trabalhos de diagnóstico já realizados (Franco, 1995).

Com relação ao controle de erosão, a conservação dos solos por meio de políticas obrigatórias quase sempre não atinge seus objetivos. $\mathrm{O}$ uso de práticas mecânicas de forma isolada também não tem sido efetivo, principalmente devido ao elevado custo para os agricultores. Porém, quando desenvolvidas com a participação e cooperação dos proprietários rurais, têm maiores possibilidades de êxito, desde que observados os seus interesses e que as práticas mecânicas sejam integradas a outras medidas de melhoria do sistema de produção.

O controle de erosão hídrica pelas árvores é obtido devido aos efeitos: a) redução no impacto da chuva no solo; b) aumento na infiltração de água no solo; c) manutenção do teor adequado de matéria orgânica na superfície do solo; e d) efeito agregador das partículas de solo (Houghton, 1984). Todos estes fatores concorrem para reduzir o escorrimento superficial de água no solo. Em estudos realizados para medir o efeito de diferentes sistemas de cobertura vegetal do solo no controle de erosão e escoamento superficial de água, em relação a florestas tropicais úmidas, constatou-se que a maior eficiência foi obtida em sistemas com mais de um estrato de cobertura vegetal (Chen, 1993).

Segundo Young (1997), os efeitos do manejo agroflorestal na manutenção da fertilidade do solo podem ser considerados como um fator direto no controle da erosão, além da proteção devido à cobertura do solo fornecida pelas copas das árvores e da manta orgânica e 
do papel das árvores como barreira ao escorrimento superficial.

As evidências do papel e do potencial da agrossilvicultura para o controle da erosão apresentam-se de duas formas. Primeiro, existem estudos experimentais com base em sistemas de uso da terra que incluem cobertura por árvores, dos quais algumas inferências podem ser feitas, baseadas nos efeitos comuns das árvores sobre os fatores causadores de erosão. Segundo, existem medidas de taxas de erosão em sistemas agroflorestais, em condições experimentais, mas estes ainda são poucos. Young (1997) fez uma revisão dos resultados de taxas de erosão em florestas tropicais, plantios florestais e sistemas agroflorestais, classificando-as, quanto aos valores, da seguinte forma:

- Baixa ( $<2$ t/ha/ano): florestas naturais, fase de pousio florestal em sistemas de agricultura itinerante, sistemas agroflorestais multiestratificados ("home garden"), plantios de árvores com culturas anuais e, ou, cobertura morta.

- Moderada (de 2 a 10 t/ha/ano): fase de cultivo agrícola em agricultura itinerante, fase de cultivo agrícola em sistema agroflorestal seqüencial.

- Alta (> 10 t/ha/ano): plantações florestais capinadas e manejadas com queima da manta orgânica.

Os sistemas agroflorestais podem ser utilizados na recuperação de áreas que foram degradadas pelas atividades agropecuárias na região, principalmente aquelas cujos fatores de produção são ineficientes para recomposição natural de seu potencial produtivo. Nestas situações, torna-se necessário oferecer condições para que os produtores rurais possam adotar tecnologias simples e de baixo custo, apropriadas para o uso e a conservação do solo, e que possam, ao mesmo tempo, garantir um nível de renda compatível ao investimento requerido para recuperação de terras degradadas.

O objetivo deste estudo foi quantificar as taxas de erosão em sistemas agroflorestais, comparadas com as dos sistemas de cultivo convencionais implantados em propriedades de pequenos agricultores, em projeto de monitoramento participativo de sistemas agroflorestais.

\section{MATERIAL E MÉTODOS}

A Zona da Mata de Minas Gerais está situada na região sudeste do Estado, no domínio da Floresta
Atlântica. Apresenta clima tropical de altitude: temperatura média de $18{ }^{\circ} \mathrm{C}$, precipitação média anual de $1.500 \mathrm{~mm}$, com 2-4 meses secos por ano. A paisagem é acidentada, com declividades que variam de 20 a $45 \%$ e com altitudes comuns que variam de 200 a $1.800 \mathrm{~m}$ (Golfari, 1975). No passado, a floresta semidecidual praticamente cobriu toda a região, mas hoje resta pouco mais que $7 \%$ da vegetação original (Dean, 1996). Os tipos de solo predominantes são Latossolos profundos e bem drenados, porém ácidos e pobres em nutrientes disponíveis.

Os sistemas foram implantados como unidades experimentais de observação das condições socioambientais dos agricultores, utilizando metodologias participativas (Quadro 1). Essas unidades experimentais apresentam dificuldades para quantificação da erosão, quando são utilizadas as metodologias convencionais. A dinâmica do manejo utilizado pelos agricultores dificulta o uso de métodos que dependem da implantação de equipamentos permanentes.

Além disso, os métodos que exigem o isolamento das parcelas produzem efeitos de borda que mascaram os resultados, quando comparados com o sistema aberto conduzido por agricultores. Os métodos que utilizam coletores individuais são adaptados para quantificação da erosão nas condições de campo; dentre os coletores, o recipiente de Gerlach (Gerlach, 1967) é o mais usado. No entanto, a irregularidade da superfície do solo nas condições das áreas manejadas pelos pequenos agricultores não permite o ajuste da borda do recipiente com $0,5 \mathrm{~m}$ de largura. As dimensões do equipamento e a necessidade de fixá-lo dificultam o seu uso em sistemas que exigem tratos culturais manuais freqüentes.

Dessa forma, foi desenvolvido um coletor de água e solo para superar essas limitações, projetado pelo professor Anor Fiorini de Carvalho, do Departamento de Solos da Universidade Federal de Viçosa (UFV). O equipamento é composto por uma "mesa" de 0,20 $\mathrm{m}$ de largura, que é inserida no solo, acoplada a uma calha móvel que sustenta um saco plástico. O solo proveniente do escorrimento superficial foi seco em estufa e, em seguida, pesado em balança eletrônica no Laboratório de Física do Solo da UFV. Quando a quantidade de solo coletado foi suficiente, foram realizadas análises de conteúdo dos nutrientes fósforo, potássio, cálcio e magnésio, segundo a metodologia proposta pela Empresa Brasileira de Pesquisa Agropecuária - EMBRAPA (1979), e dos teores de carbono orgânico, pelo processo Walkey-Black (Defelipo \& Ribeiro, 1981).

R. Árvore, Viçosa-M G, v.26, n.6, p.751-760, 2002 
As análises foram feitas no Laboratório de Manejo e Conservação de Solos da UFV. Os valores de perda de solos obtidos nas coletas foram convertidos em quilos por hectare, levando-se em conta a largura do aparelho, a distância entre os aparelhos e o comprimento da rampa que contribui para a erosão em cada aparelho.

Foram instalados coletores em 25 unidades de observação, sendo 14 sistemas convencionais e 11 sistemas agroflorestais. Dentre as unidades, cinco constituem uma área experimental pertencente à UFV. O número de aparelhos instalados por Unidade de Observação (UO) foi diretamente relacionado ao comprimento da curva de nível situada na metade da rampa de maior declive de cada unidade (Quadro 2). Os dados foram coletados na estação chuvosa de 1998/1999.

Cada medida de perda de solo tomada pelos coletores foi relacionada à energia da chuva que promoveu o arraste das partículas. A energia dos eventos erosivos (erosividade) foi calculada a partir de pluviogramas, conforme Nill et al. (1996), a partir de dados registrados pela estação climatológica da UFV. A estimativa da erosividade média anual das chuvas em Viçosa foi adotada a partir dos cálculos realizados por Boarett et al. (1998). Com base nas erosividades das chuvas que promoveram a erosão medida pelos coletores e na erosividade média anual de Viçosa, foram estimadas as perdas anuais de solo potenciais para cada sistema estudado.

Com o objetivo de analisar a influência de alguns fatores na perda de solos nos sistemas estudados, foram medidas a cobertura do solo e a declividade. A cobertura do solo foi avaliada por meio do uso de um gabarito metálico de $1 \mathrm{~m}^{2}$, composto de quatro quadrantes. Estimou-se, visualmente, a porcentagem de solo coberto em cada quadrante e, em seguida, extraiu-se a média do quadrante para obter o valor da cobertura acima de cada aparelho. A declividade acima de cada aparelho também foi medida por um clinômetro, tendo os valores sido expressos em porcentagem.

Para comparar as características nos diferentes sistemas de produção, foi utilizado o teste paramétrico de Mann-Whitney, de acordo com Snedecor \& Cochran (1980). Este teste foi escolhido devido à não-normalidade e à heterogeneidade de variâncias, mesmo após as transformações de dados. Realizou-se, ainda, uma análise de regressão, utilizando como variáveis independentes a cobertura do solo e a declividade no local de instalação do aparelho e como variável dependente, a perda de solo.

\section{RESULTADOS E DISCUSSÕES}

A metodologia utilizada permitiu obter as taxas de perda de solo por ha/ano e os nutrientes nele contidos, para diferentes sistemas de uso da terra (Quadro 3). Podese observar que os dados estão dentro das faixas de valores encontrados na literatura, que variam de $0,01 \mathrm{t} / \mathrm{ha} / \mathrm{ano}$, para ecossistemas naturais e sistema agroflorestal multiestratificado ("home garden"), a 47 t/ha/ano, para plantações de árvores sem cobertura morta e plantas invasoras (Young, 1997). Outros autores, como Montagnini (1992), apresentam valores de $0,09 \mathrm{t} / \mathrm{ha} / \mathrm{ano}$ para florestas tropicais, e para culturas agrícolas valores de $4 \mathrm{t} / \mathrm{ha} / \mathrm{ano}$ para milho, $11 \mathrm{t} / \mathrm{ha} /$ ano para arroz e 1,20 t/ha/ano para pastagens. Observa-se na literatura e também nos dados obtidos que os valores de perdas para sistemas potencialmente mais sujeitos à erosão apresentam uma grande variação, indicando que a importância do manejo realizado é maior que a natureza do sistema praticado.

Observa-se que nos sistemas agroflorestais (SAFs) as perdas de solo e de nutrientes foram muito menores que as dos sistemas convencionais, o que mostra o grande potencial dos SAFs para conservação do solo e, conseqüentemente, para garantir a maior sustentabilidade aos agricultores. A variação de perda de solo nos SAFs foi de 6,8 a $578,5 \mathrm{~kg} / \mathrm{ha} / \mathrm{ano}$, sendo comparável às das comunidades florestais, e nos sistemas convencionais variou de 20,2 a 22.183,9 kg/ha/ano (Figura 1). A diferença na variação entre os dois sistemas, considerados como tratamentos, foi analisada ( $\mathrm{F}=1.018,90$ e $\mathrm{P}=0,001)$, constatando-se que as variâncias são heterogêneas, não podendo ser avaliadas por meio de testes paramétricos de média. Este fato mostra a grande estabilidade dos sistemas agroflorestais em relação à proteção do solo e, por outro lado, a instabilidade dos sistemas convencionais, comprovando assim que a erosão constitui um sério problema da agricultura praticada nas condições agroecológicas da região.

Os SAFs apresentaram perda média de solo de $217,3 \mathrm{~kg} / \mathrm{ha} / \mathrm{ano}$, inferior à dos sistemas convencionais, que apresentaram perda média de $2.611,9 \mathrm{~kg} / \mathrm{ha} /$ ano ( $\mathrm{U}=32,00$ e $\mathrm{P}=0,014)$.

Em relação às estimativas de perdas de nutrientes pela erosão do solo nos sistemas estudados, observa-se (Figura 2) que os sistemas convencionais apresentaram a maior perda para todos os nutrientes analisados e também para o carbono orgânico. O cálcio e o magnésio foram os nutrientes que apresentaram os maiores valores de perda, tanto nos sistemas convencionais quanto nos SAFs. 


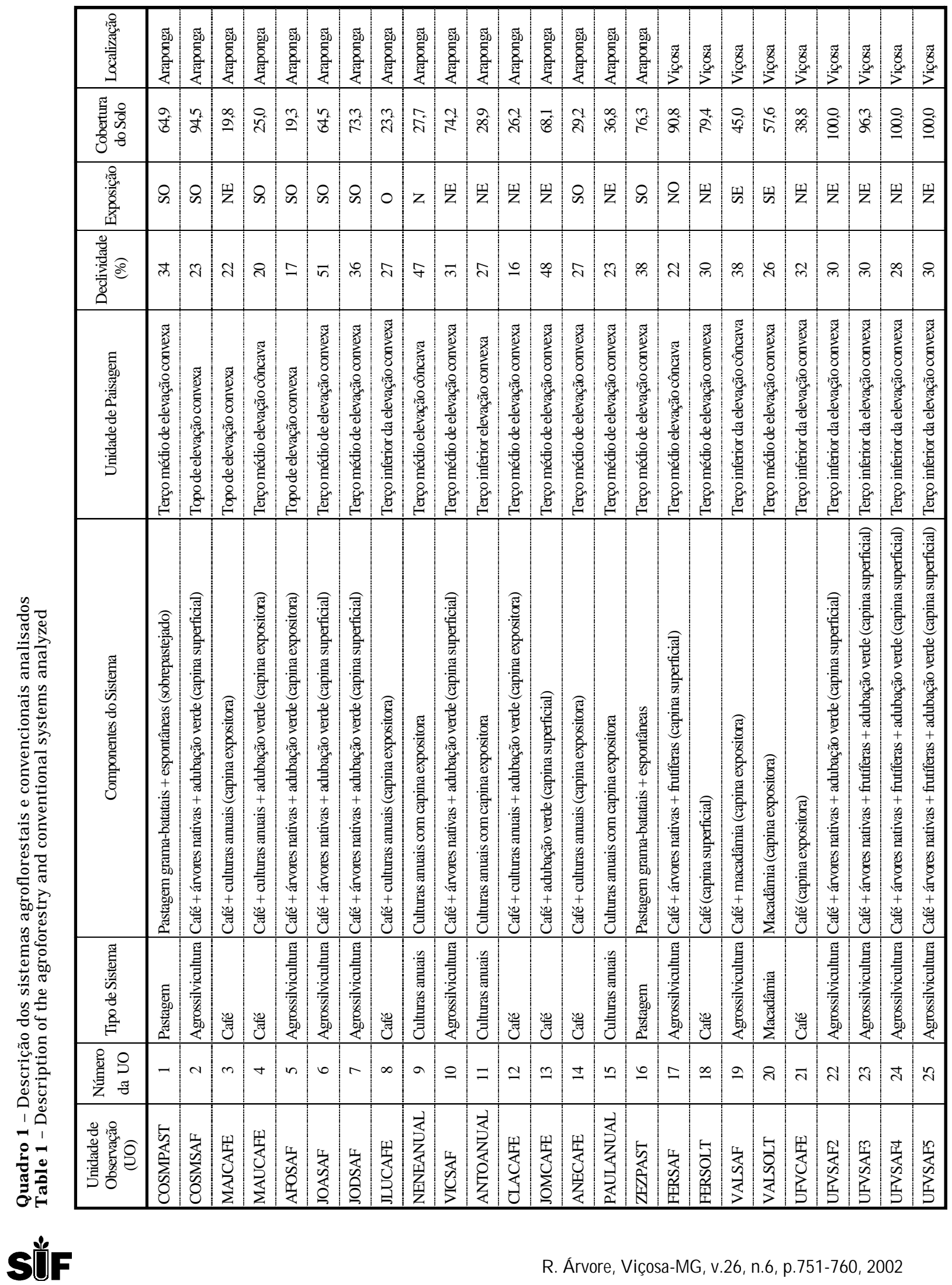


Quadro 2 - Número de aparelhos instalados nas unidades de observação estudadas

Table 2 - Number of collectors installed in the observation units studied

\begin{tabular}{|c|l|}
\hline $\begin{array}{c}\text { Número de Aparelhos por Unidade } \\
\text { de Observação }\end{array}$ & Número das Unidades de Observação \\
\hline 4 & $21-22-23-24-25$ \\
\hline 5 & $1-2-3-4-5-6-7-8-9-10-11-12-14-15-16$ \\
\hline 7 & $19-20$ \\
\hline 8 & $13-17-18$ \\
\hline
\end{tabular}

Tal comportamento pode estar relacionado ao fato de que em alguns dos sistemas é realizada a calagem, ficando alguma quantidade do nutriente à superfície, o que facilita a sua retirada. De qualquer forma, trata-se de uma perda considerável de nutrientes que estariam cumprindo, principalmente, as funções de ocupar o complexo de troca do solo e nutrir as plantas. O P e o $\mathrm{K}$, apesar de apresentarem valores menores de perdas, no caso do sistema convencional tiveram valores consideráveis, pois constituem fontes de saída que, quando somadas aos nutrientes que são extraídos pelas colheitas das culturas, contribuem para diminuir cada vez mais a sustentabilidade desses sistemas de produção.

Quadro 3 - Resultados obtidos de perda de solos e nutrientes nos sistemas agroflorestais e convencionais na Zona da Mata de Minas Gerais

Table 3 - Loss of soil and nutrients under agroforestry and conventional systems in Zona da Mata de Minas Gerais

\begin{tabular}{|c|c|c|c|c|c|c|c|}
\hline Número & Sistema & $\begin{array}{c}\text { Solo } \\
\text { (kg/ha/ano) }\end{array}$ & $\begin{array}{c}\mathrm{CO} \\
\text { (kg/ha/ano) }\end{array}$ & $\begin{array}{c}\mathrm{P} \\
\text { (g/ha/ano) }\end{array}$ & $\begin{array}{c}\mathrm{K} \\
\text { (g/ha/ano) }\end{array}$ & $\begin{array}{c}\mathrm{Ca} \\
\text { (g/ha/ano) }\end{array}$ & $\begin{array}{c}\mathrm{Mg} \\
\text { (g/ha/ano) }\end{array}$ \\
\hline \multicolumn{8}{|c|}{ Sistemas Agroflorestais } \\
\hline 17 & FERSAF & 6,8 & - & - & - & 10,9 & 2,1 \\
\hline 10 & VICSAF & 53,3 & 2,4 & 0,2 & 4,1 & 42,7 & 10,9 \\
\hline 19 & VALSAF & 90,4 & 5,9 & 6,9 & 18,6 & 138,4 & 37,6 \\
\hline 5 & AFOSAF & 90,8 & 3,2 & 0,4 & 5,5 & 50,9 & 10,9 \\
\hline 2 & COSMSAF & 118,2 & 3,7 & 0,5 & 3,3 & 26,0 & 4,3 \\
\hline 6 & JOASAF & 197,1 & 8,4 & 0,6 & 7,7 & 212,8 & 35,5 \\
\hline 7 & JODSAF & 198,6 & 5,9 & 1,2 & 8,9 & 162,8 & 23,8 \\
\hline 22 & UFVSAF2 & 214,5 & - & - & - & - & - \\
\hline 24 & UFVSAF4 & 419,6 & - & - & - & - & - \\
\hline 23 & UFVSAF3 & 423,1 & - & - & - & - & - \\
\hline 25 & UFVSAF5 & 578,5 & - & - & - & - & - \\
\hline & Média & 217,3 & 4,9 & 1,6 & 8,0 & 92,1 & 17,9 \\
\hline \multicolumn{8}{|c|}{ Sistemas Convencionais } \\
\hline 18 & FERSOL & 20,2 & 1,1 & 0,7 & 4,4 & 14,1 & 4,5 \\
\hline 12 & CLACAFE & 199,2 & 5,8 & 1,3 & 10,4 & 278,9 & 31,1 \\
\hline 20 & VALSOL' & 249,8 & 10,6 & 10,9 & 33,6 & 280,2 & 83,3 \\
\hline 3 & MAJCAFE & 255,5 & 8,7 & 1,1 & 5,6 & 168,6 & 21,5 \\
\hline 4 & MAUCAFE & 259,2 & 10,8 & 2,6 & 4,9 & 165,9 & 24,9 \\
\hline 16 & ZEZPAST & 264,5 & 11,2 & 1,2 & 11,9 & 290,9 & 25,4 \\
\hline 14 & ANECAFE & 370,3 & 11,6 & 2,6 & 20,4 & 444,3 & 84,4 \\
\hline 13 & JOMCAFE & 394,2 & 8,8 & 3,5 & 18,5 & 323,2 & 61,5 \\
\hline 1 & COSMPAST & $1.028,5$ & 43,7 & 4,6 & 14,4 & $1.090,2$ & 61,7 \\
\hline 15 & PAULAGRI & $1.085,5$ & 14,3 & 7,1 & 53,2 & 825,0 & 221,4 \\
\hline 9 & NENEAGRI & $1.293,4$ & 17,1 & 1,6 & 19,4 & 569,1 & 93,1 \\
\hline 11 & ANTOAGRI & $1.503,8$ & 35,2 & 5,3 & 43,6 & $1.383,5$ & 415,0 \\
\hline 8 & JLUCAFE & $2.788,6$ & 36,8 & 19,5 & 64,1 & $2.565,5$ & 635,8 \\
\hline \multirow[t]{2}{*}{21} & UFVCAFE & $22.183,9$ & 581,2 & 504,7 & $3.692,9$ & $1.4508,2$ & $5.856,5$ \\
\hline & Média & 2611,9 & 65,1 & 46,5 & 328,3 & 1865,5 & 625,3 \\
\hline
\end{tabular}




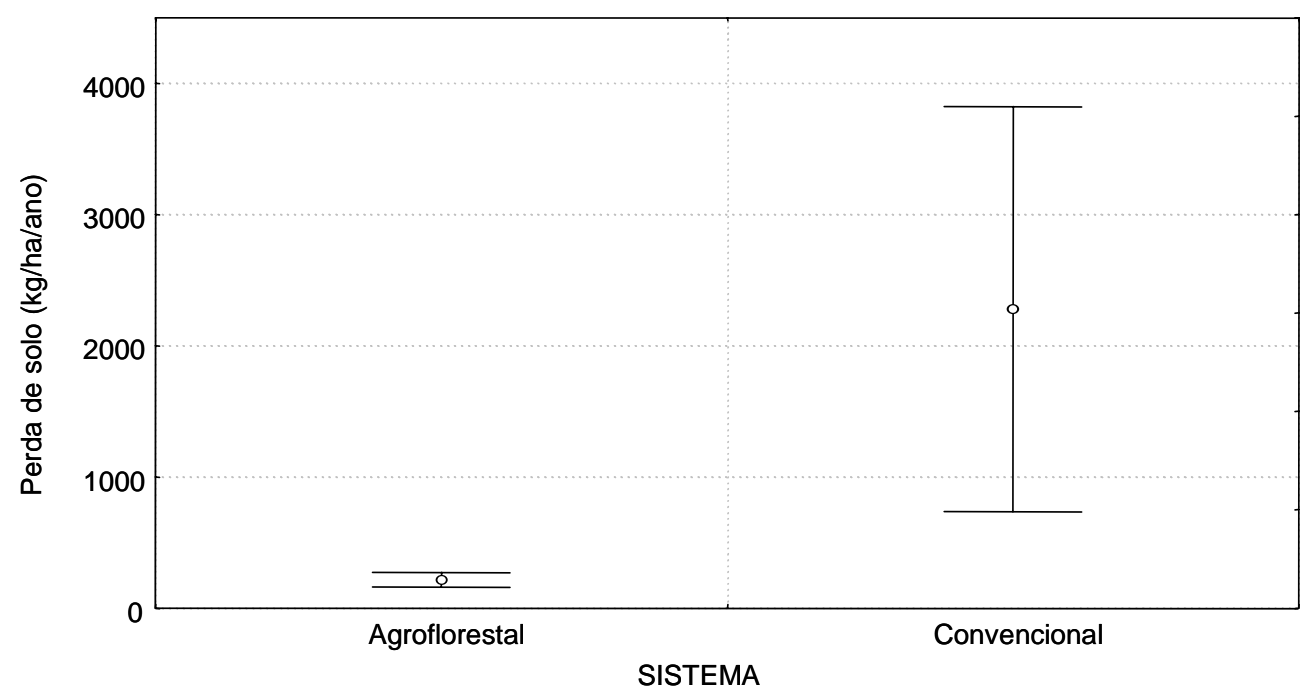

Figura 1 - Comparação entre a variação das perdas de solo nos sistemas agroflorestais e convencionais na Zona da Mata de Minas Gerais.

Figure 1 - Comparison between variation of soil losses in agroforestry and conventional systems in Zona da Mata de Minas Gerais.
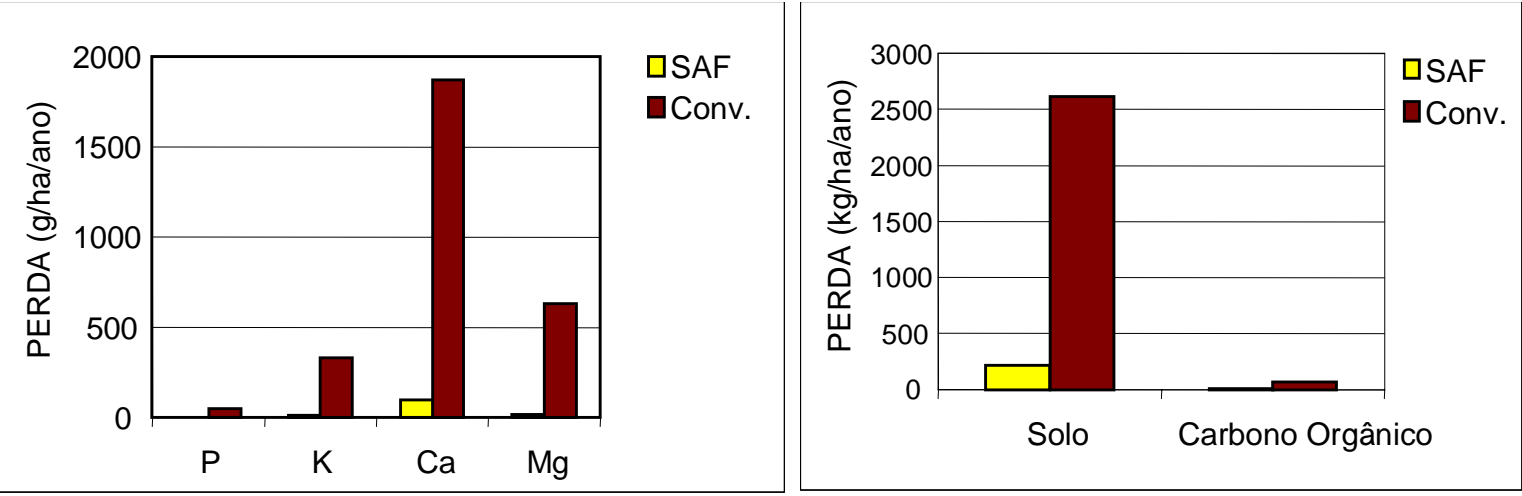

Figura 2 - Perdas de solo, carbono orgânico e nutrientes nos sistemas agroflorestais e convencionais na Zona da Mata de Minas Gerais.

Figure 2 - Losses of soil, organic carbon and nutrients under agroforestry and conventional systems in Zona da Mata de Minas Gerais.

O carbono orgânico apresentou valores de perda bastante significativos, principalmente para os sistemas convencionais. Este fato reforça a idéia de que o horizonte superficial dos solos, onde fica a camada mais fértil pelo maior conteúdo de matéria orgânica, fica empobrecida e degradada ao longo dos anos, devido aos processos erosivos. Uma das consequiências da diminuição da matéria orgânica no solo é justamente a sua desestruturação, o que facilita ainda mais o processo de escorrimento superficial.
Considerando que esses nutrientes retirados pela chuva são levados para os locais mais baixos, até atingirem os aqüíferos superficiais, os SAFs apresentam grande potencial como alternativa para diminuir a poluição dos recursos hídricos, que representa também um fator de degradação ambiental.

Os resultados obtidos para as análises de regressão realizadas para perda em função da cobertura e da declividade não apresentaram significância estatística, possivelmente devido à influência conjunta de outros

R. Árvore, Viçosa-M G, v.26, n.6, p.751-760, 2002 
fatores que atuam de forma mais acentuada no processo erosivo, além de possíveis interferências pela forma de coleta dos dados e da amostragem (Quadro 4).

Quadro 4 - Resultados das análises de regressão realizadas para os dados obtidos para os SAFs e para os sistemas convencionais

Table 4 - Results of regression analysis for agroforestry and conventional systems

\begin{tabular}{|c|c|c|c|}
\hline Sistema & $\mathrm{B}$ & $\mathrm{t}$ & $\mathrm{p}$ \\
\hline Agroflorestal & & & \\
Cobertura & 2,60 & 1,53 & 0,15 \\
Declividade & 1,10 & 0,22 & 0,82 \\
\hline Convencional & & & \\
Cobertura & $-43,23$ & $-0,39$ & 0,69 \\
Declividade & 85,49 & 0,34 & 0,73 \\
\hline
\end{tabular}

No entanto, os dados (Figuras 3 e 4) mostraram a tendência esperada, que é o aumento da erosão com a diminuição da cobertura e o aumento da declividade, porém no caso dos SAFs a influência da cobertura foi positiva.

Uma explicação pode ser que a cobertura do solo, obtida pela medição da infestação de plantas invasoras e também da cobertura morta, promove a proteção eficiente do solo. No caso dos SAFs, devido ao sombreamento, a incidência de espontâneas é menor, e a proteção maior passa a ser devido à interceptação da chuva pelas copas das árvores. Outro fator observado é que a grande adição de matéria orgânica ao solo, proporcionada pelas podas e pela queda das folhas das árvores, contribui para melhorar as características físicas do solo, aumentando a infiltração e diminuindo o escorrimento superficial.

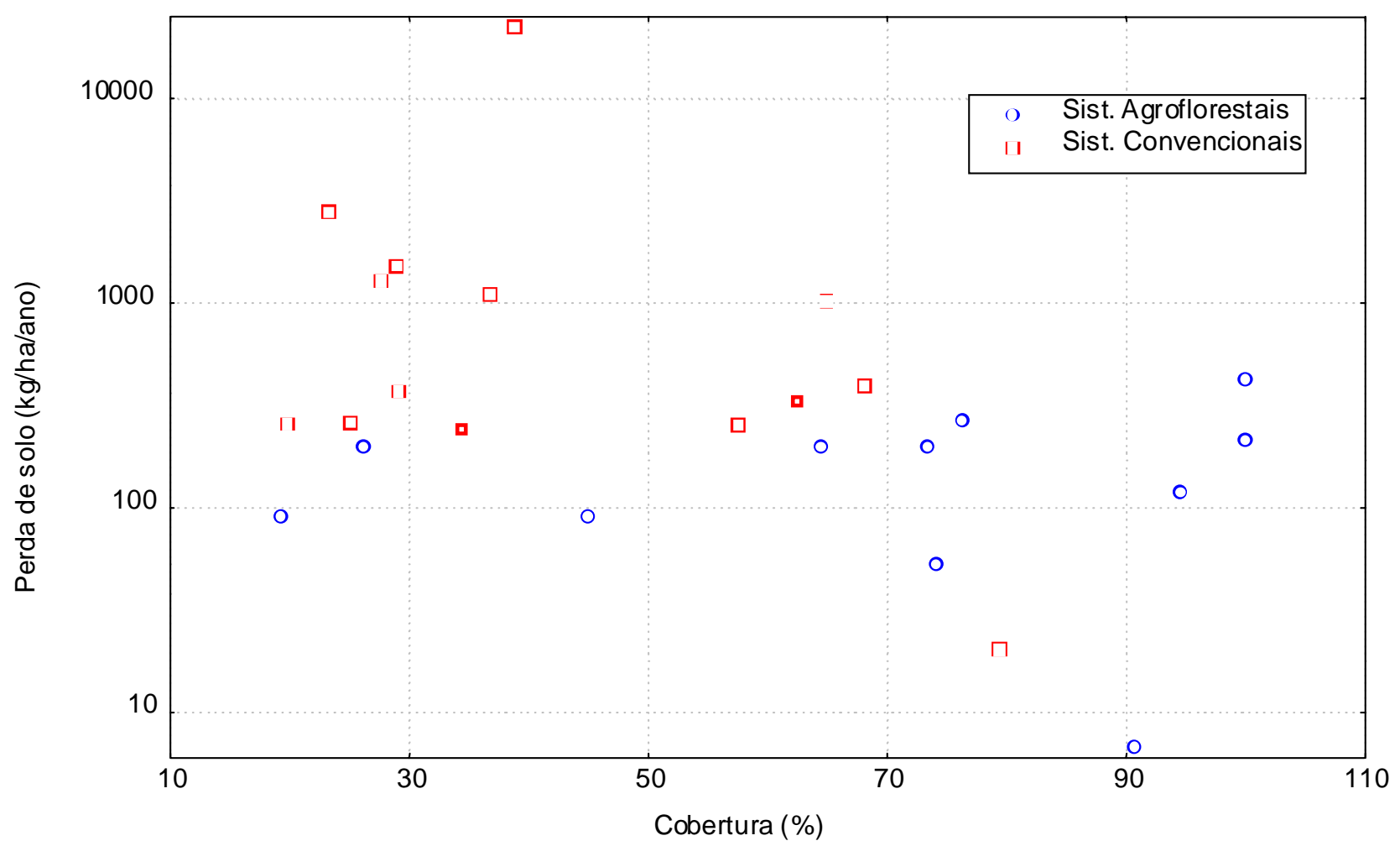

Figura 3 - Dispersão dos dados de perda de solo em função da cobertura do solo para sistemas agroflorestais e convencionais na Zona da Mata de Minas Gerais.

Figure 3 - Soil loss data dispersion in function of soil coverage under agroforestry and conventional systems in Zona da Mata de Minas Gerais. 


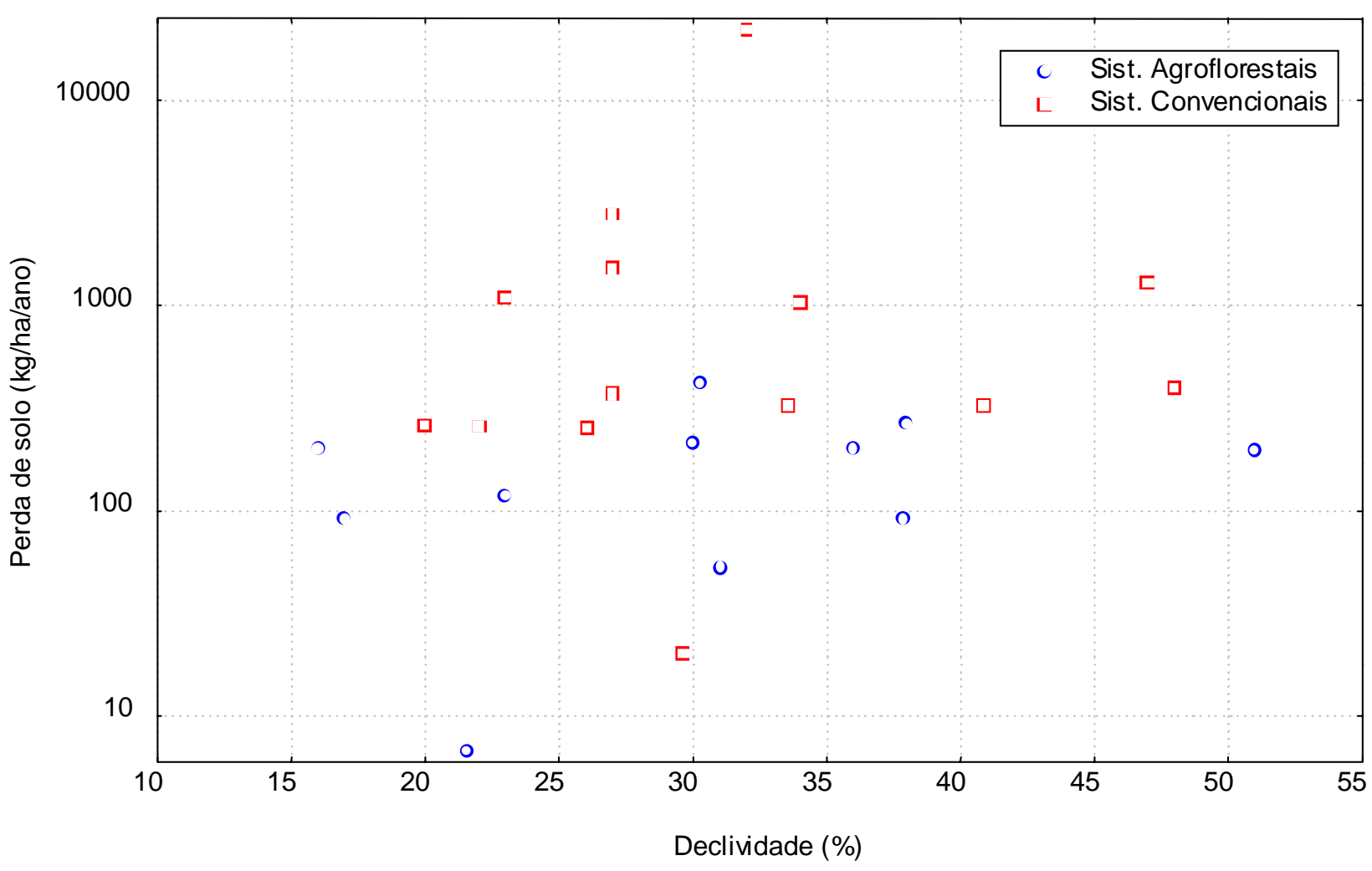

Figura 4 - Dispersão dos dados de perda de solo em função da declividade para sistemas agroflorestais e convencionais na Zona da Mata de Minas Gerais.

Figure 4-Soil loss data dispersion in function of hillslope under agroforestry and conventional systems in Zona da Mata de Minas Gerais.

\section{CONCLUSÕES}

Os resultados evidenciam o grande potencial dos sistemas agroflorestais como estratégia para conservação dos solos em microbacias, quando comparados com os sistemas convencionais normalmente utilizados na região da Zona da Mata. Além disto, tais sistemas podem ajudar a diminuir a poluição dos recursos hídricos, ocasionada pelo escorrimento superficial de nutrientes e produtos químicos utilizados na agricultura. As perdas totais de solo, carbono orgânico e nutrientes dos sistemas convencionais, estimadas para um ano, foram significativamente maiores do que as dos sistemas agroflorestais, o que indica a maior sustentabilidade ecológica dos últimos, evidenciando a necessidade da busca de sistemas mais conservadores dos recursos naturais do que os convencionais utilizados na região.
O método utilizado para quantificação da erosão por meio de coletores instalados nas unidades de observação em propriedades de agricultores mostrou-se eficiente como um indicador de sustentabilidade, para a comparação e para o monitoramento de diferentes sistemas de uso da terra.

Além disso, o método apresenta um grande valor como forma de difusão e aprendizado para os agricultores, devido à praticidade e facilidade de constatação dos resultados, podendo ser utilizado para demonstração da eficiência de práticas de manejo na conservação do solo. Outro aspecto é que o método reúne várias características desejáveis para indicadores de sustentabilidade, como: fácil medição; aplicabilidade a uma ampla faixa de ecossistemas e sistemas econômico-sociais; coleta de dados fácil e econômica; a população envolvida pode participar das medições; e as medições permitem a repetição ao longo do tempo.

R. Árvore, Viçosa-M G, v.26, n.6, p.751-760, 2002 


\section{REFERÊNCIAS BIBLIOGRÁFICAS}

BOARETT, W. A.; SOUZA, C. M.; WRUCK, F. J. Índice de Erosividade das Chuvas para Viçosa-MG. Revista Ceres, v. 45, n. 258, p. 193-201, 1998.

CHEN, C. P. Pastures as the secondary component in treepasture systems. In: INTERNATIONAL GRASSLAND CONGRESS, 17., 1993. Rockhampton. Proceedings ... Rockhampton: 1993 . v. 3. p. 2037-2043.

DEAN, W. A ferro e fogo: a história e a devastação da mata atlântica brasileira. São Paulo: Companhia das Letras, 1996. $484 \mathrm{p}$.

DEFELIPO, B. V.; RIBEIRO, A. C. Análise química do solo (metodologia). Viçosa: UFV, 1981. 17 p. (Boletim de Extensão, 29).

EMPRESA BRASILEIRA DE PESQUISA

AGROPECUÁRIA - EMBRAPA. Serviço Nacional de Levantamento e Conservação de Solos. Manual de método de análises de solo. Rio de Janeiro: 1979. não paginado.

FERRARI, E. A. Desenvolvimento da agricultura familiar: a experiência do CTA-ZM. In: ALVARES V., V. H.; FONTES, L. E. F.; FONTES, M. P. F. (Eds.). O solo nos grandes domínios morfoclimáticos do Brasil e o desenvolvimento sustentado. Viçosa: JARD, 1996. p.233250 .
FRANCO, F. S. Diagnóstico e desenho de sistemas agroflorestais em microbacias hidrográficas no município de Araponga, Zona da Mata de Minas Gerais. ViçosaMG: UFV, 1995. 110 p. Dissertação (Mestrado em Ciência Florestal) - Universidade Federal de Viçosa, 1995.

GERLACH, T. Hillslope troughs for measuring sediment movement. Review Géomorphologia Dynamics, v. 17, p. $173,1967$.

GOLFARI, L. Zoneamento ecológico do Estado de Minas Gerias para reflorestamento. Belo Horizonte: CPFRC, 65 p. 1975. (Série Técnica, 3).

GOMES, S. T. Condicionantes da modernização do pequeno agricultor. São Paulo: Ipê, 1986. 181 p.

HOUGHTON, D. Trees and erosion control. Queensland Agricultural Journal, v. 110, n. 1, p. 9-12, 1984.

MONTAGNINI, F. Sistemas agroflorestales: principios y aplicaciones en los tropicos, San José: 1992. 622 p.

NILL, D. et al. Soil erosion by water in África. Rossdorf: GTZ, 1996. 164 p.

SNEDECOR, G. W.; COCHRAN, W. G. Statistical methods. Ames: University Press, 1980. 507 p.

YOUNG, A. Agroforestry for soil management. 2.ed. Wallingford: ICRAF and CAB International, 1997. 320 p. 